\title{
Single-incision video-assisted thoracoscopic resection of a pedunculated solitary fibrous tumor of the pleura: case report
}

Masaya Tamura*, Yosuke Shimizu and Yasuo Hashizume

\begin{abstract}
In this report, we describe the surgical resection of a pedunculated solitary fibrous tumor of the pleura (SFTP) by single-incision thoracoscopic surgery (SITS). SITS may be a suitable surgical option for pedunculated SFTPS.
\end{abstract}

Keywords: Single-incision thoracoscopic surgery, Solitary fibrous tumor of the pleura, Video-assisted thoracoscopic surgery

\section{Background}

Solitary fibrous tumor of the pleura (SFTP) is a relatively rare pleural tumor that generally arises from the visceral pleura as an asymptomatic pleural-based mass [1]. We present a case of SFTP, which was initially diagnosed as a thymoma during a preoperative computed tomography (CT) scan. We describe the first case of a pedunculated SFTP, resected by minimally invasive single-incision thoracoscopic surgery (SITS). Furthermore, we discuss the advantages and disadvantages of several practical treatments.

\section{Case presentation}

An 81-year-old woman was admitted to our hospital for further examination of an abnormal shadow found on a chest CT. She had a history of thymectomy for thymoma. A CT scan demonstrated a homogenous, sharply circumscribed mass in the anterior mediastinum (Figure 1). The preoperative diagnosis was given as recurrent thymoma. However, surgery was required to arrive at a pathological diagnosis and for curative resection. The patient was given general anesthesia using one-lung ventilation and was placed in a semilateral position. Exploration through the left fifth intercostal space using a $5 \mathrm{~mm}$ trocar was performed. No tumor was found in the thymic tissue. However, a pedunculated tumor that protruded into the thoracic cavity from the visceral pleura was observed. The tumor

\footnotetext{
* Correspondence: masatamu2007@yahoo.co.jp

Department of Surgery, Fukui Prefectural Hospital, Yotsui 2-8-1, Fukui 910-8526, Japan
}

\section{Ciomed Central}

(c) 2013 Tamura et al.; licensee BioMed Central Ltd. This is an Open Access article distributed under the terms of the Creative Commons Attribution License (http://creativecommons.org/licenses/by/2.0), which permits unrestricted use, distribution, and reproduction in any medium, provided the original work is properly cited.

\section{Discussion}

Solitary fibrous tumor of the pleura is a type of mesenchymal tumor that tends to involve the pleura. Although most SFTPs are considered histologically benign, local recurrences and enlargements without any sign of invasion or metastasis have been reported [2]. Video- assisted thoracoscopic surgery is thought to be minimally invasive;

was attached by its stalk to the left upper lobe, and moved freely (Figure 2B). We believed that a single-port surgery was feasible for this type of lesion.

The $5 \mathrm{~mm}$ incision was extended to $2.5 \mathrm{~cm}$, and the wound retraction system (Alexis Wound Retractor, Applied Medical, Rancho Santa Margarita, CA USA) was then placed through the incision (Figure 2A). The tumor was suspended using articulating endograspers (Covidien, Norwalk, C1, USA) and was resected using an not perform frozen section during the procedure. Because the tumor was pedunculated and relatively small, it could be resected with sufficient margin.

Microscopically, the tumor was characterized by spincollagenous background. Areas of high cellularity and mitotic activity were absent (Figure 3). Immunohistochemical staining was strongly positive for CD34, bcl-2, and vimentin in the cytoplasm of the tumor cells. The tumor was determined to be a benign SFTP. The patient was followed up for 6 months, and no evidence of recurrence was observed. 

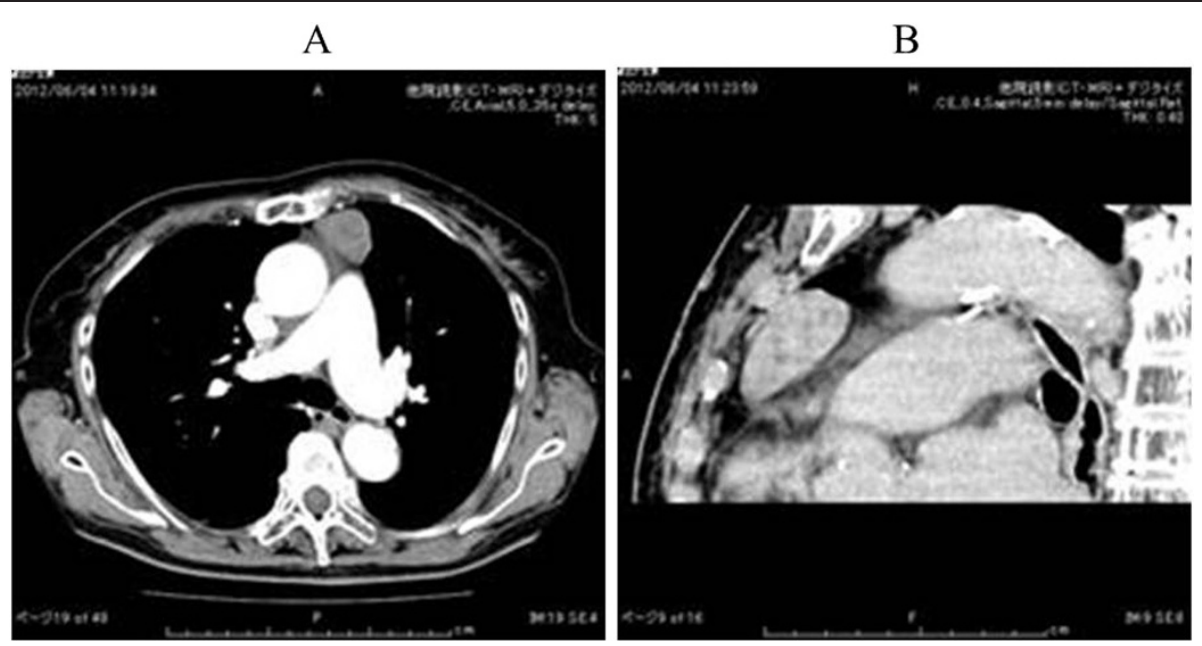

Figure 1 Preoperative chest computed tomography (CT) scan demonstrated a homogenous, sharply circumscribed mass in the anterior mediastinum. (A): Enhancement showed a mass that was not enhanced. (B) Sagittal view.

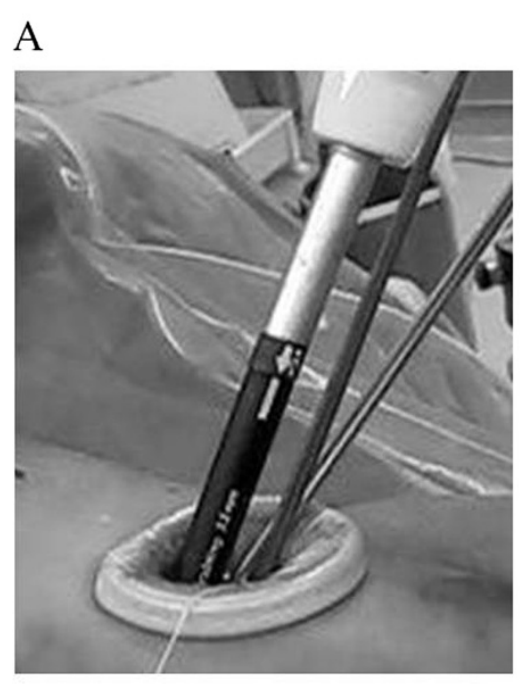

$\mathrm{B}$

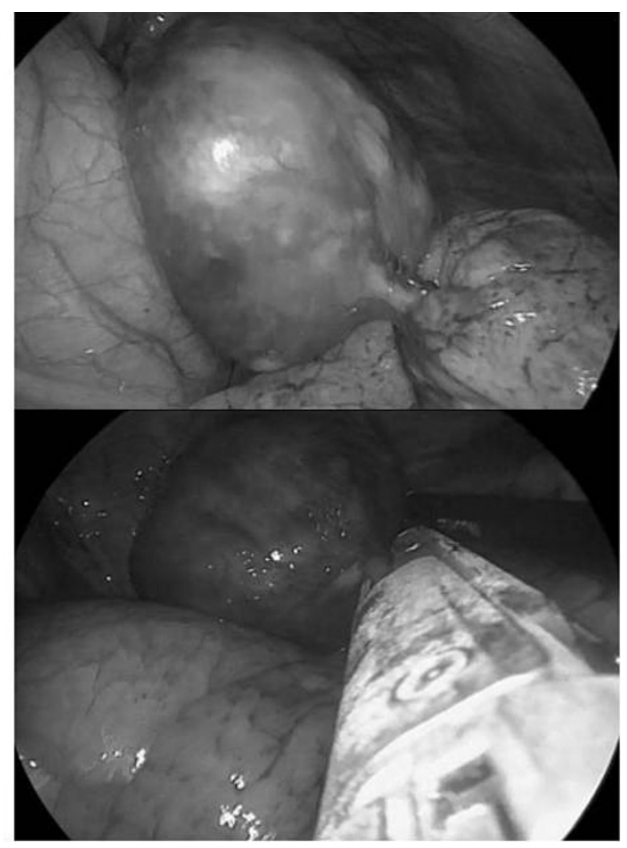

Figure 2 Intraoperative findings. (A) A $2.5 \mathrm{~cm}$ skin incision was made, and a wound retraction system (Alexis Wound Retractor, Applied Medical, Rancho Santa Margarita, CA USA) was placed through the incision. (B) A pedunculated tumor protruded into the thoracic cavity from the visceral pleura, and was attached to the left upper lobe. (C) The tumor stalk was resected using an articulating endostapler (Covidien, Norwalk, CT, USA). 


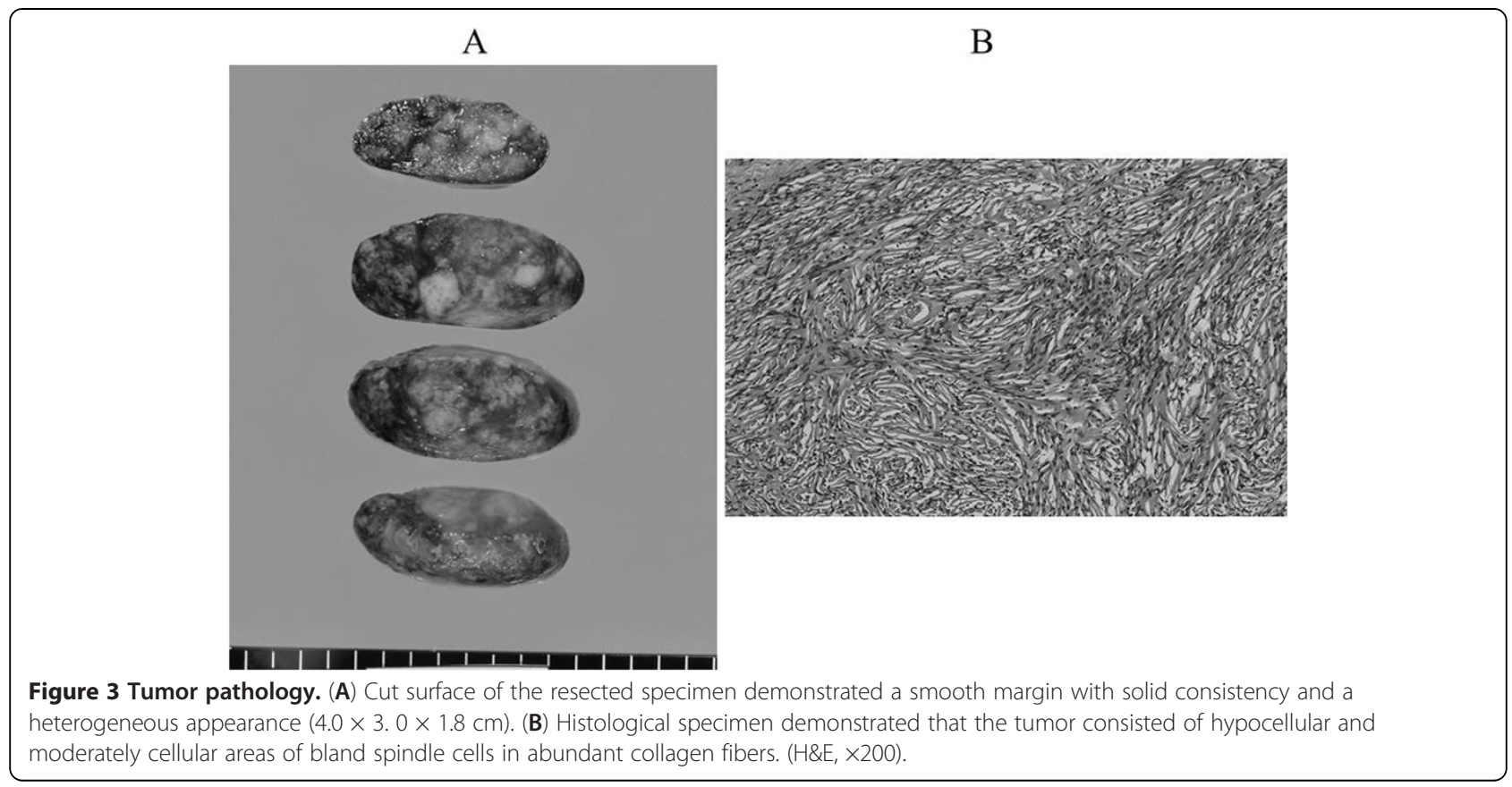

therefore, it is perceived to result in less postoperative pain and faster recovery [3]. Takahama et al. [4] reported that VATS is a powerful and useful approach for pedunculated tumors.

Recently, VATS has become a more commonly used technique for thoracic tumor surgeries [5]. In particular, single-port VATS has been useful for specific diseases, such as pneumothorax [6]. To the best of our knowledge, there have been no previous reports on the use of single-port VATS for SFTP. Because only one intercostal space is involved, the possible advantages of SITS over conventional three-port VATS include less postoperative pain, fewer postoperative drainage days, shorter hospital stays, and cosmetic advantages. Some authors have reported less postoperative pain and less paresthesia in patients who underwent minor procedures through a single-port approach than with the classical three-port approach $[7,8]$.

There are obvious technical problems with single-port thoracoscopic surgery. It is not a naturally ergonomic procedure, because the traditional thoracoscopic principles of triangulation are lost. In addition, positioning of multiple devices poses a problem because they are passed through a single small incision in the chest. Instruments often interfere with each other, not only within the pleural space, but also in the extrapleural space, where such attachments as a camera light lead often impede movements. To overcome these limitations, the development of new instruments is needed. Increasing the length of the camera shaft will allow an assistant to stand comfortably with his or her hands away from those of the surgeon. Use of a rotary articulating endograsper aids in achieving triangulation and assists with the use of other devices, with good results.

Nomori et al. [9] reported that contact metastasis and local recurrence occur at the port site. In the case presented here, the tumor was resected through a $2.5 \mathrm{~cm}$ incision wound, even though the tumor was $4.0 \mathrm{~cm}$ in diameter. A wound retraction system should provide for wound dilation and protection when a specimen is to be removed through a small incision. Initially, the patient's tumor was thought to be a recurrent thymoma. In general, median sternotomy is planned for a thymoma. When the diagnosis is suspected preoperatively, using a single-port VATS can contribute to the avoidance of obvious excessive invasion.

\section{Conclusion}

In conclusion, we recommend minimally invasive singleport VATS for resecting a thoracic pedunculated SFTP.

\section{Consent}

'Written informed consent was obtained from the patient for publication of this report and any accompanying images'.

\section{Abbreviations}

CT: Computed tomography; H\&E: Hematoxylin and eosin; SFTP: Solitary fibrous tumor of the pleura; SITS: Single-incision thoracoscopic surgery; VATS: Video- assisted thoracoscopic surgery.

\section{Competing interests}

The authors declare that they have no competing interests. 
Authors' contribution

M T drafted the manuscript. Y S and Y H participated in the sentence alignment and editorial work of the picture. All authors read and approved the final manuscript.

Received: 26 January 2013 Accepted: 12 May 2013

Published: 22 May 2013

\section{References}

1. Harrison-Phipps KM, Nichols FC, Schleck CD, Deschamps C, Cassivi SD, Schipper PH, Allen MS, Wigle DA, Pairolero PC: Solitary fibrous tumors of the pleura: results of surgical treatment and long-term prognosis. $J$ Thorac Cardiovasc Surg 2009, 138:19-25.

2. de Perrot M, Fischer $S$, Brundler MA, Sekine Y, Keshavjee S: Solitary fibrous tumors of the pleura. Ann Thorac Surg 2002, 74:285-293.

3. Li WW, Lee TW, Lam SS, Ng CS, Sihoe AD, Wan IY, Yim AP: Quality of life following lung cancer resection: video-assisted thoracic surgery vs thoracotomy. Chest 2002, 122:584-589.

4. Takahama M, Kushibe K, Kawaguchi T, Kimura M, Taniguchi S: Videoassisted thoracoscopic surgery is a promising treatment for solitary fibrous tumor of the pleura. Chest 2004, 125:1144-1147.

5. Shapiro M, Weiser TS, Wisnivesky JP, Chin C, Arustamyan M, Swanson SJ: Thoracoscopic segmentectomy compares favorably with thoracoscopic lobectomy for patients with small stage I lung cancer. J Thorac Cardiovasc Surg 2009, 137:1388-1393.

6. Gigirey Castro O, Berlanga Gonzalez L, Sanchez GE: Single port thoracoscopic surgery using the SILS tool as a novel method in the surgical treatment of pneumothorax. Arch Bronconeumol 2010, 46:439-441.

7. Salati M, Brunelli A, Xiume F, Refai M, Sciarra V, Soccetti A, Sabbatini A: Uniportal video-assisted thoracic surgery for spontaneous pneumothorax: clinical and economic analysis in comparison to the traditional approach. Interact Cardiovasc Thorac Surg 2008, 7:63-66.

8. Jutley RS, Khalil MW, Rocco G: Uniportal vs standard three-port VATS technique for spontaneous pneumothorax: comparison of postoperative pain and residual paraesthesia. Eur J Cardiothorac Surg 2005, 28:43-46.

9. Nomori $\mathrm{H}$, Horio $\mathrm{H}$, Fuyuno $\mathrm{G}$, Morinaga $\mathrm{S}$ : Contacting metastasis of a fibrous tumor of the pleura. Eur J Cardiovasc Surg 1997, 12(6):928-30.

doi:10.1186/1477-7819-11-105

Cite this article as: Tamura et al:: Single-incision video-assisted

thoracoscopic resection of a pedunculated solitary fibrous tumor of the pleura: case report. World Journal of Surgical Oncology 2013 11:105.

\section{Submit your next manuscript to BioMed Central and take full advantage of:}

- Convenient online submission

- Thorough peer review

- No space constraints or color figure charges

- Immediate publication on acceptance

- Inclusion in PubMed, CAS, Scopus and Google Scholar

- Research which is freely available for redistribution 